\title{
Psoriatic Arthritis: What is Happening at the Joint?
}

\author{
Jennifer Belasco • Nathan Wei
}

Received: March 12, 2019 / Published online: May 17, 2019

(C) The Author(s) 2019

\section{ABSTRACT}

Psoriatic arthritis (PsA) is a heterogeneous and inflammatory disease with diverse clinical manifestations, including psoriasis, nail psoriasis, peripheral joint disease, axial joint disease, enthesitis, and dactylitis. Typically, this varied clinical presentation complicates the clinician's ability to distinguish PsA from other forms of arthritis. In the synovium of individuals with PsA, upregulation of the genes WNT3A, BMPR2, and TGFBR1 results in bone erosion and new bone formation, a pattern unique to the disease. Additionally, genes associated with angiogenesis and vascularization such as $V E G F$ and TGFB1 facilitate inflammation and joint damage. Gross pathogenesis of PsA is driven by proinflammatory cytokines, and key cytokines affecting joint structures include tumor necrosis factor- $\alpha$, interleukin (IL)-6, IL-17A, IL-21, IL-22, and

Dr. Wei died March 27, 2018.

Enhanced Digital Features To view enhanced digital features for this article go to https://doi.org/10.6084/ m9.figshare.8025668.

J. Belasco $(\square)$

Clinical Investigation, Laboratory of Investigative

Dermatology, The Rockefeller University, New York, NY, USA

e-mail: jbelasco@rockefeller.edu

N. Wei

Arthritis Treatment Center, Frederick, MD, USA
IL-23. Early diagnosis is critical for providing treatment that prevents irreversible disease progression and function loss. This narrative review discusses differentiation of PsA from other forms of arthritis. Additionally, we detail the role of cytokines at the joint in mediating PsA pathogenesis.

Funding: Novartis Pharmaceuticals Corporation.

Keywords: Cytokines; Differential diagnosis; Inflammation; Joints; Psoriatic arthritis

\section{INTRODUCTION}

Psoriatic arthritis (PsA) is a heterogeneous, inflammatory disease characterized by involvement of the following domains: psoriasis, nail psoriasis, peripheral joint disease, axial joint disease, enthesitis, and dactylitis [1-3]. Clinical manifestations vary greatly between patients. PsA can present with oligoarticular joint involvement that is typically asymmetric or as polyarticular disease affecting five or more joints, usually with a symmetric distribution similar to that of rheumatoid arthritis (RA) [3, 4]. In approximately $5 \%$ of cases, PsA can present with arthritis mutilans, which is a severe, destructive, deforming manifestation characterized by telescoping digits [5]. Some patients with PsA show symptoms only in distal joints (e.g., interphalangeal hand and foot joints, 
including distal interphalangeal joints), while others have disease that predominantly affects the axial skeleton (i.e., spine and sacroiliac joints) [1]. Nail pitting, onycholysis, and hyperkeratosis also affect many patients with PsA, and the presence of enthesitis can differentiate patients with PsA from those with RA $[2,6]$. Additionally, inflammatory bowel disease and uveitis are characteristic extra-articular manifestations that affect a small but significant proportion of patients with PsA [1, 7].

This diversity in clinical features makes PsA challenging for healthcare practitioners to distinguish from other forms of arthritis [8]. Delayed diagnosis of PsA is associated with irreversible disease progression, and optimized early treatment with disease-modifying therapies can slow such progression and improve physical function and quality of life $[9,10]$. This narrative review discusses key differences between PsA and other arthropathies, with specific emphasis on the unique ways in which PsA affects joint structure and function and how new therapies with different mechanisms of action target different cytokine drivers of disease pathophysiology.

This narrative review is based on previously conducted studies and does not contain any studies with human participants or animals performed by the authors.

\section{DIFFERENCES BETWEEN PSA AND OTHER FORMS OF ARTHRITIS}

\section{Differences in Gene Expression}

At the gene expression level, PsA is characterized by a unique pattern compared with skin and synovium from healthy people, and patients with other forms of arthritis (e.g., RA, osteoarthritis, and systemic lupus erythematosus) [11]. Characteristically, locally upregulated genes in PsA synovium include Wnt family member 3A (WNT3A), bone morphogenetic protein receptor type II (BMPR2), and transforming growth factor beta receptor 1 (TGFBR1) [11]. This distinct synovial gene expression pattern is consistent with observations of both bone erosion and new bone formation in PsA, a combination that is not seen in other rheumatic conditions [12]. Specifically, WNT3A is associated with bone development and osteoblast function; BMPR2 encodes type II bone morphogenic protein (BMP) receptor, which regulates endochondral bone formation; and TGFBR1 encodes transforming growth factor beta receptor 1 , which regulates extracellular matrix production [13-15]. It is believed that such complex patterns of diverse gene and protein expression drive bone destruction and formation in PsA, rather than a single pathogenic molecular pathway.

In addition to upregulation of these genetic markers of bone changes, genes that control processes associated with angiogenesis and vascularization [e.g., vascular endothelial growth factor (VEGF) and transforming growth factor beta 1 (TGFB1)] are upregulated in the synovium of patients with PsA $[11,16]$. This upregulation of angiogenic pathways facilitates inflammation, synovial fibroblast activation, and joint damage [16]. Furthermore, in skin samples of patients with PsA, strong upregulation of genes related to the proinflammatory cytokine interleukin (IL)-17 has been observed [11]. These gene expression patterns in PsA are consistent with observations that increased vascularity and skin inflammation are more common in PsA than in other types of arthritis [17].

\section{Differential Diagnosis}

Although genetic profiling is a useful research tool that has helped elucidate expression patterns that can distinguish PsA from other arthropathies, differential diagnosis in daily practice requires assessment of clinical signs and symptoms. Table 1 provides a comparison of key features of PsA, RA, ankylosing spondylitis (AS), gout, and osteoarthritis that can aid in differential diagnosis. Dactylitis (diffuse swelling of an entire digit) is uncommon in other types of arthritis, with the exception of gout or pseudogout [18]. However, because dactylitis is estimated to affect up to $50 \%$ of patients with PsA [1], its absence cannot be used to exclude a diagnosis of PsA. Enthesitis (inflammation adjacent to joints at tendon, ligament, or joint- 
Table 1 Clinical characteristics of different types of arthritis that can aid differential diagnosis $[1,3,4,86-90]$

\begin{tabular}{llllll}
\hline Clinical characteristic & PsA & RA & AS & Gout & OA \\
\hline Number of affected joints & Poly- or oligoarticular & Polyarticular & Mono- or oligoarticular & Mono- or oligoarticular & Mono- or oligoarticular \\
Joint distribution at onset & Usually asymmetric & Usually symmetric & Symmetric & Asymmetric & Asymmetric \\
Sites on hands or feet & Distal & Proximal & NA & Distal & Distal \\
Areas involved & All joints of a digit & Some joints of a digit & Limited to spine/SIJs & Mono- or polyarticular & Same joint across digits \\
Spinal involvement & Common & Uncommon & Present & Absent & Noninflammatory \\
Sacroiliitis & Common (unilateral) $)$ & Absent & Present (bilateral) & Absent & Absent \\
Psoriasis & Common & Uncommon & Uncommon & Uncommon & Uncommon \\
Enthesitis & Common & Present & Common & Absent & Absent \\
Dactylitis & Common & Uncommon & Present & Sometimes observed & Absent \\
Nail dystrophy & Common & Absent & Uncommon & Absent & Absent \\
Synovial vascularity & Increased & Lower & Lower & Lower & Lower \\
\hline
\end{tabular}

$A S$ ankylosing spondylitis, $N A$ not applicable, $O A$ osteoarthritis, $P s A$ psoriatic arthritis, $R A$ rheumatoid arthritis, $S I J$ sacroiliac joint

${ }^{\text {a }}$ May be confused with podagra

b vs PsA

capsule insertions) has an estimated prevalence of $35 \%$ in PsA and is hypothesized to be a triggering mechanism of PsA $[19,20]$. The enthesis organ is key for dissipating biomechanical stress, which results in the production of cytokines $[19,21]$. The ability of individuals to resolve inflammation at the enthesis organ may be impaired in PsA, leading to elevated production of cytokines that can enter synovial tissue and cause an articular inflammatory response $[19,21,22]$. Typically, enthesitis of the distal interphalangeal joint is observed during the early stages of PsA, and the close relationship between the nail, tendon attached to bone, and periosteum may explain the high frequency of nail disease in patients with PsA $[23,24]$. However, enthesitis is also common in patients with other types of spondyloarthritis, and it can be difficult to distinguish between enthesitis and tender points found in fibromyalgia $[25,26]$. Therefore, joint locations should be considered in differential diagnosis. Enthesitis associated with PsA is most common at the Achilles tendon, plantar fascia, patellar tendon insertion, quadriceps insertion, iliac crest, epicondyle, and supraspinatus tendon [27-29].

Use of imaging in clinical practice can provide important information to identify and differentiate between PsA and other types of inflammatory arthritis. Classification Criteria for Psoriatic Arthritis (CASPAR) criteria include radiographic evidence of new bone formation as a characteristic feature of PsA $[1,30]$. In contrast, radiographic changes in RA include demineralization and uniform bone loss, without new bone formation [31, 32]. Other characteristic features of PsA that can be identified on ultrasound include ankylosis, enthesitis, cortical bone erosions, cartilage lesions, and synovitis [33, 34]. In the severe arthritis mutilans subtype of PsA, osteolysis can be identified radiographically on the basis of observations of bone resorption, pencil-in-cup deformities, total joint erosion, and subluxation [4].

Synovial joint inflammation, which is a common feature of many types of inflammatory arthritis, can also be visualized on ultrasound. The appearance of synovitis, as thickened, hypoechoic, nondisplaceable intra-articular tissue, is similar in PsA and other forms of arthritis [35]. However, joint distribution may vary, with synovitis of the distal interphalangeal joints being more common in PsA than in RA [36]. Additionally, flexor tenosynovitis associated with dactylitis is a common feature on imaging that is highly suggestive of PsA [30, 37].

Sacroiliitis is also a common feature of PsA that is not present in RA or osteoarthritis [1]. 
Magnetic resonance imaging (MRI) of the sacroiliac joint is extremely useful for identification of sacroiliitis and differential diagnosis of axial spondyloarthritis [38]. Unilateral sacroiliitis with bulky paramarginal and vertical syndesmophytes (i.e., bony growths extending from spinal ligaments) can be used to differentiate PsA from AS, in which axial involvement is usually bilateral and without paramarginal syndesmophytes [1].

\section{ROLE OF CYTOKINES AT THE JOINT}

Different molecular pathways involving several proinflammatory cytokines have been shown to drive PsA pathogenesis (for a summary figure on the pathogenic pathways in PsA, please see the manuscript by Ritchlin and colleagues, which is referenced here [1]). When thinking about the roles of different cytokines in joint-related manifestations of PsA, consider the joint as being similar to an organ system, much like the heart in the cardiovascular system. Tissue from all parts of the joint, including synovium, cartilage, subchondral bone, and entheses, should be analyzed to determine which cytokines are expressed in which tissues.

Overall, PsA pathogenesis is driven by innate and adaptive immune inflammatory responses of T helper 17 (Th17) cells and key cytokines in joint structures, including tumor necrosis factor- $\alpha$ (TNF), IL-6, IL-17A, IL-21, IL-22, and IL-23 $[1,16,39]$. A small body of research has indicated that increased serum levels of the proinflammatory cytokine IL-33 and synovial tissue levels of the angiogenic cytokine IL-18 were also correlated with inflammation in patients with psoriatic disease [40-42].

Inflammation induced by biomechanical stress has been demonstrated to induce changes to the entheses. In a murine model of TNF overexpression, inflammation is observed at the synovial-entheseal complex of the Achilles tendon at approximately 4 weeks of age and hind-limb unloading significantly suppresses inflammation of the Achilles tendon compared with weight-bearing controls [43]. In another murine model of arthritis, IL-23 receptor expression is increased at entheseal interfaces between tendons and bones at axial joints [44]. IL-23 binding to these receptors stimulates expression of IL-17A and IL-22, which triggers enthesitis and the severity of enthesitis was correlated with IL-17A and IL-22 levels [44]. Furthermore, Reinhardt and colleagues recently showed that in mice subjected to conditions of inflammation and mechanical stress, entheseal $\gamma / \delta$ cells produced high levels of IL-17A at anatomic locations commonly affected by spondyloarthritis (e.g., the Achilles tendon entheses) [45]. These types of preclinical studies have provided strong evidence supporting that IL-17 is the key cytokine driver of the Th17/IL-23 axis in PsA joint pathogenesis; however, research in humans is needed to confirm these findings.

In the synovium of patients with PsA, the Th17 axis is a driver of inflammation, although B cells may also play a minor role in synovial inflammation [11]. In contrast, in RA, synovial B cells are regulators of immune-mediated inflammatory responses [11]. Surprisingly, IL-6 signaling is increased in the synovium of patients with PsA when compared to lesional skin [11]; however, on the basis of mixed results of case studies of the IL- 6 inhibitor tocilizumab, in patients with PsA, this cytokine is likely not a main driver of disease in the joint [46-48]. Axial involvement in spondyloarthritis is driven by IL-17, which is a key contributor to RANKL-induced bone erosion and joint destruction [49]. Menon and colleagues have shown that joints affected by PsA (but not RA) were enriched with IL-17+ CD8+ T cells, and that levels of these $\mathrm{T}$ cells were correlated with disease activity and progression of joint disease [50].

A proteomic analysis of synovial fluid from patients with PsA identified 12 proteins that were at significantly greater levels compared with synovial fluid from patients with early osteoarthritis [51]. Most of the identified proteins (e.g., alpha defensin 1, myeloperoxidase, and CD5-like protein) play functional roles in pathways that are dysregulated in psoriasis or PsA [51]. Moreover, at the onset of PsA, the synovial fluid of some patients has been described to be inflammatory in nature, to have decreased viscosity, and to have increased number of leukocytes (predominantly polymorphonucleates) [52]. Further studies are warranted to determine whether characteristics 
of synovial fluid or levels of specific proteins in synovial fluid can be used as a reliable diagnostic marker and/or therapeutic target for PsA.

Cartilage degradation in PsA has been linked to upregulation of TNF and subsequent increased production of matrix metalloproteinases (MMPs) from macrophages [53]. Other proteins encoded by genetic regulators of cartilage and bone breakdown and formation include MMP1, which degrades collagen in the extracellular matrix; collagen type II, alpha 1, which regulates skeletal growth and development; WNT1 inducible signaling pathway protein 1 , which is a connective tissue growth factor; hyaluronan synthase $I$, which drive synthesis of extracellular matrices during tissue repair; integrin-binding sialoprotein, which is a structural protein in bone matrices and is associated with synovial inflammation; type II BMP receptor, which regulates endochondral bone formation; and Wnt-3a, a ligand associated with osteoblast function and bone development [11].

\section{EARLY DETECTION, MONITORING, AND TREATMENT OF PSA}

As the inflammatory burden associated with PsA increases, so does the patient's risk of irreversible joint damage [50], making early identification essential. In contrast to RA, in which laboratory tests for biomarkers (e.g., rheumatoid factor and anti-citrullinated protein antibody) are routinely used as diagnostic and prognostic tools, no validated serum or synovial biomarkers are used in clinical practice to monitor for PsA [54]. However, identification of such biomarkers is an area of active research. For example, dendritic cellspecific transmembrane protein (DC-STAMP), which plays important roles in osteoclast formation, myeloid cell differentiation, and immune function, has been identified at significantly higher concentrations in the bone marrow of patients with PsA compared with healthy controls [55]. Other biomarkers that have shown promise in PsA include BMP4, MMP3, TNF-superfamily molecules, Dickkopf-related protein (DKK)-1, and macrophage colony-stimulating factor (M-CSF) [56-58]. However, studies of some of these potential biomarkers have evaluated peripheral blood concentrations [55, 56, 58], which is of limited usefulness in assessing disease activity and predicting response to treatment. Biomarkers isolated from tissue samples would be more useful for such purposes.

In the absence of reliable biomarkers to assess or predict joint damage, clinical evaluation of patients with suspected PsA should include physical examination and use of imaging modalities, such as ultrasound and MRI, to detect low-grade joint inflammation or enthesitis $[6,59,60]$. The selection of entheseal sites to evaluate in PsA is important as ultrasound of the synovial-entheseal complex of the small joints in the hand differentiates between early PsA and early RA [6]. Ultrasound has also proved more sensitive than clinical examination in detecting entheseal abnormalities in early PsA [61]. Development of PsA is especially common in patients with psoriasis, family history of psoriasis, and/or nail dystrophy [2, 30], so these patients should be evaluated regularly for signs of joint pain, morning stiffness, and dactylitis [1]. However, because psoriasis severity is not correlated with joint disease severity, patients with mild psoriasis should also be evaluated for PsA $[62,63]$. Detection of enthesitis can be critical to identifying patients with early PsA. In patients with psoriasis, enthesitis is the primary lesion that precedes development of the skeletal manifestations of PsA [64, 65]. Additionally, peripheral enthesitis may be the only rheumatologic symptom in a subset of patients with PsA [66].

Delays in diagnosis and treatment of PsA are associated with poor radiographic and functional outcomes [67-69]. Thus, European League Against Rheumatism (EULAR) recommendations for the management of PsA emphasize the importance of early pharmacologic intervention [70]. Data on the benefits of early intervention are more limited in PsA than in other arthropathies, but available evidence suggests that early intervention and tight control of inflammation significantly reduces joint pain and swelling and improves quality of life for patients with PsA [71, 72]. However, the impact of early intervention on radiographic outcomes and costeffectiveness is less certain; more research is needed to better understand the effect of different treatment modalities on these variables [71]. 
In recent years, several disease-modifying antirheumatic drugs have been approved for the treatment of PsA, expanding the therapeutic armamentarium to include agents with several mechanisms of action. Having treatment options that act on different molecular targets is especially beneficial for managing a disease as clinically and genetically heterogeneous as PsA [73].

As new data on the genetic profiles of different types of arthritis have emerged, it has become clear that PsA and psoriasis have genetic similarities but PsA has little or no genetic overlap with other types of arthritis (especially RA) [74]. These findings suggest that just because therapies are effective for one type of arthritis, they may not provide comparable levels of efficacy for PsA or other arthropathies [74]. While TNF inhibitors are approved for the treatment of both RA and PsA, they act on upstream targets of PsA pathogenesis, providing relatively nonspecific modulation of angiogenesis, osteoclastogenesis, and synovial inflammation [75]. As such, many patients with PsA fail to respond to TNF inhibitors, which have demonstrated low rates of long-term achievement of remission [76].

Newer therapies targeting more downstream, disease-specific cytokines associated with the Th17/IL-23 axis have demonstrated significant clinical efficacy in patients with PsA [73]. The IL-17A inhibitor secukinumab is approved for the treatment of adults with active PsA or AS, and another IL-17A inhibitor, ixekizumab, is approved for active PsA and is in late-stage clinical development for active AS (both secukinumab and ixekizumab are also approved for the treatment of moderate-to-severe plaque psoriasis). The IL-12/23 antagonist ustekinumab was also recently approved for the treatment of active PsA, in addition to previous approvals for the treatment of psoriasis and Crohn's disease. The IL-23specific inhibitor guselkumab was recently approved for the treatment of moderate-to-severe plaque psoriasis, and clinical trials in PsA are ongoing. Consistent with genetic profiling results showing that expression of IL-17 is significantly higher in skin than in synovium in patients with PsA [11], and that IL-17 and IL-23 expression is not increased in all patients with PsA, agents targeting these cytokines are particularly efficacious in skin disease [73]. Additionally, secukinumab, ixekizumab, and ustekinumab provide significant improvements in both skin and joint symptoms in patients with PsA who have failed to respond to anti-TNF therapies [77-79].

Overall, data indicate that expression patterns of genes associated with PsA pathogenesis are heterogeneous [80]. Therefore, the efficacy of treatments with different mechanisms of action will vary between patients, with all available therapies currently demonstrating only limited effectiveness against bone changes associated with PsA [73]. Unfortunately, at present, predicting a patient's response to a given medication is not possible. Thus, healthcare practitioners should monitor patients regularly for clinical response to therapy and switch therapies if patients do not experience a satisfactory response to any given treatment [73].

Clinical response to therapy can be monitored in several ways. Perhaps the most important component of treatment response assessment is the patient's overall impression of how well a therapeutic regimen is working. Generally, patient satisfaction with treatment accompanies improvement in assessments of PsA disease activity using instruments, such as Minimal Disease Activity (MDA), Psoriatic Arthritis Response Criteria (PsARC), Disease Activity in Psoriatic Arthritis (DAPSA), and the Composite Psoriatic Disease Activity Index (CPDAI) $[67,81,82]$. These instruments include assessment of symptoms known to be burdensome to patients, including joint pain, tenderness, and swelling; psoriasis; dactylitis; enthesitis; and patient-reported outcomes related to the impact of disease on quality of life [81]. The psoriatic arthritis disease activity score (PASDAS) and the GRAPPA composite exercise (GRACE) index are weighted composite measures that provide single scores for disease activity and responder indices [83]. PASDAS and the GRACE index include assessments of quality of life, patient global scores, and physician global scores [83]. Interestingly, both PASDAS and the GRACE index performed significantly better in discriminating between subjects according to the decision to change treatment at baseline compared with CPDAI or DAPSA [83]. Evaluation of serum C-reactive protein concentration is also a key 
Table 2 Key unanswered questions on how the joint is affected in PsA

Do entheses drive development of PsA in humans?

What is the significance of connections between nail disease and enthesitis?

What characteristics of entheseal tissue are associated with disease mechanisms?

What molecular pathways in bone tissue are involved in bone erosion and formation?

Is there a connection between the skin and the joint in PsA?

Can cells that are activated at the skin affect the joint?

Ps $A$ psoriatic arthritis

criterion of many definitions for PsA remission $[81,84]$, and normalization of erythrocyte sedimentation rate has been associated with increased likelihood of achieving MDA [85].

\section{UNANSWERED QUESTIONS}

While significant progress has been made in recent years expanding our understanding of the molecular mechanisms and genetic profiles of PsA pathogenesis, future research is needed to address key unanswered questions about how the joint is affected in PsA (Table 2). However, researchers are finding that obtaining funding for such studies is increasingly difficult. It is hoped that better understanding of these issues will provide insight into disease mechanisms responsible for joint damage in PsA.

\section{ACKNOWLEDGEMENTS}

Funding. Sponsorship for this study and the article processing charges were funded by Novartis Pharmaceuticals Corporation. Both authors had full access to the articles reviewed in this manuscript and take complete responsibility for the integrity and accuracy of this manuscript.

Editorial Assistance. Editorial assistance in the preparation of this manuscript was provided by Scott Forbes, PhD of Oxford PharmaGenesis Inc., Newtown, PA, USA and was funded by Novartis Pharmaceuticals Corporation.
Authorship. Both named authors met the International Committee of Medical Journal Editors (ICMJE) criteria for authorship for this article, took responsibility for the integrity of the work as a whole, and had given approval for this version to be published.

Disclosures. Jennifer Belasco and Nathan Wei (deceased) had nothing to disclose.

Compliance with Ethics Guidelines. This narrative review is based on previously conducted studies and does not contain any studies with human participants or animals performed by any of the authors.

Data Availability. Data sharing is not applicable to this article as no datasets were generated or analyzed during the current study.

Open Access. This article is distributed under the terms of the Creative Commons Attribution-NonCommercial 4.0 International License (http://creativecommons.org/licenses/ by-nc/4.0/), which permits any noncommercial use, distribution, and reproduction in any medium, provided you give appropriate credit to the original author(s) and the source, provide a link to the Creative Commons license, and indicate if changes were made.

\section{REFERENCES}

1. Ritchlin CT, Colbert RA, Gladman DD. Psoriatic arthritis. N Engl J Med. 2017;376:957-70. 
2. Coates LC, Helliwell PS. Psoriatic arthritis: state of the art review. Clin Med (Lond). 2017;17:65-70.

3. Gladman DD. Clinical features and diagnostic considerations in psoriatic arthritis. Rheum Dis Clin N Am. 2015;41:569-79.

4. Acosta Felquer ML, FitzGerald O. Peripheral joint involvement in psoriatic arthritis patients. Clin Exp Rheumatol. 2015;33:S26-30.

5. Haddad A, Johnson SR, Somaily M, et al. Psoriatic arthritis mutilans: clinical and radiographic criteria. A systematic review. J Rheumatol. 2015;42:1432-8.

6. Zabotti A, Salvin S, Quartuccio L, De Vita S. Differentiation between early rheumatoid and early psoriatic arthritis by the ultrasonographic study of the synovio-entheseal complex of the small joints of the hands. Clin Exp Rheumatol. 2016;34:459-65.

7. Charlton R, Green A, Shaddick G, et al. Risk of uveitis and inflammatory bowel disease in people with psoriatic arthritis: a population-based cohort study. Ann Rheum Dis. 2018;77:277-80.

8. Mortezavi M, Thiele R, Ritchlin C. The joint in psoriatic arthritis. Clin Exp Rheumatol. 2015;33:S20-S2525.

9. Haroon M, Gallagher P, FitzGerald O. Diagnostic delay of more than 6 months contributes to poor radiographic and functional outcome in psoriatic arthritis. Ann Rheum Dis. 2015;74:1045-50.

10. Mease PJ, Armstrong AW. Managing patients with psoriatic disease: the diagnosis and pharmacologic treatment of psoriatic arthritis in patients with psoriasis. Drugs. 2014;74:423-41.

11. Belasco J, Louie JS, Gulati N, et al. Comparative genomic profiling of synovium versus skin lesions in psoriatic arthritis. Arthritis Rheumatol. 2015;67:934-44.

12. Rossini M, Viapiana O, Adami S, Idolazzi L, Fracassi E, Gatti D. Focal bone involvement in inflammatory arthritis: the role of IL17. Rheumatol Int. 2016;36:469-82.

13. Si W, Kang Q, Luu HH, et al. CCN1/Cyr61 is regulated by the canonical Wnt signal and plays an important role in Wnt3A-induced osteoblast differentiation of mesenchymal stem cells. Mol Cell Biol. 2006;26:2955-64.

14. Katagiri T, Watabe T. Bone morphogenetic proteins. Cold Spring Harb Perspect Biol. 2016;8:a021899.

15. Laping NJ, Grygielko E, Mathur A, et al. Inhibition of transforming growth factor (TGF)- $\beta 1$-induced extracellular matrix with a novel inhibitor of the TGF- $\beta$ type I receptor kinase activity: SB-431542. Mol Pharmacol. 2002;62:58-64.

16. Yamamoto T. Angiogenic and inflammatory properties of psoriatic arthritis. ISRN Dermatol. 2013;2013:630620.

17. Veale DJ, Fearon U. What makes psoriatic and rheumatoid arthritis so different? RMD Open. 2015; 1:e000025.

18. Healy PJ, Helliwell PS. Dactylitis: pathogenesis and clinical considerations. Curr Rheumatol Rep. 2006;8:338-41.

19. McGonagle D. Enthesitis: an autoinflammatory lesion linking nail and joint involvement in psoriatic disease. J Eur Acad Dermatol Venereol. 2009;23(Suppl 1):9-13.

20. Polachek A, Li S, Chandran V, Gladman DD. Clinical enthesitis in a prospective longitudinal psoriatic arthritis cohort: incidence, prevalence, characteristics, and outcome. Arthritis Care Res (Hoboken). 2017;69:1685-91.

21. Kehl AS, Corr M, Weisman MH. Enthesitis: new insights into pathogenesis, diagnostic modalities, and treatment. Arthritis Rheumatol. 2016;68:312-22.

22. Jacques $\mathrm{P}$, McGonagle $\mathrm{D}$. The role of mechanical stress in the pathogenesis of spondyloarthritis and how to combat it. Best Pract Res Clin Rheumatol. 2014;28:703-10.

23. Langenbruch A, Radtke MA, Krensel M, Jacobi A, Reich K, Augustin M. Nail involvement as a predictor of concomitant psoriatic arthritis in patients with psoriasis. Br J Dermatol. 2014;171:1123-8.

24. Sobolewski P, Walecka I, Dopytalska K. Nail involvement in psoriatic arthritis. Reumatologia. 2017;55:131-5.

25. Marchesoni A, Atzeni F, Spadaro A, et al. Identification of the clinical features distinguishing psoriatic arthritis and fibromyalgia. J Rheumatol. 2012;39:849-55.

26. Baraliakos $\mathrm{X}$, Braun J. Non-radiographic axial spondyloarthritis and ankylosing spondylitis: what are the similarities and differences? RMD Open. 2015; 1:e00053.

27. McGonagle DG, Helliwell P, Veale D. Enthesitis in psoriatic disease. Dermatology. 2012;225:100-9.

28. Freeston JE, Coates LC, Helliwell PS, et al. Is there subclinical enthesitis in early psoriatic arthritis? A clinical comparison with power Doppler 
ultrasound. Arthritis Care Res (Hoboken). 2012;64:1617-21.

29. Poggenborg RP, Eshed I, Østergaard M, et al. Enthesitis in patients with psoriatic arthritis, axial spondyloarthritis and healthy subjects assessed by 'head-to-toe' whole-body MRI and clinical examination. Ann Rheum Dis. 2015;74:823-9.

30. Taylor W, Gladman D, Helliwell P, et al. Classification criteria for psoriatic arthritis: development of new criteria from a large international study. Arthritis Rheum. 2006;54:2665-733.

31. Kocijan R, Finzel S, Englbrecht M, Engelke K, Rech J, Schett G. Decreased quantity and quality of the periarticular and nonperiarticular bone in patients with rheumatoid arthritis: a cross-sectional HRpQCT study. J Bone Miner Res. 2014;29:1005-144.

32. Goldring SR. Differential mechanisms of de-regulated bone formation in rheumatoid arthritis and spondyloarthritis. Rheumatology (Oxford). 2016;55:ii56-ii60.

33. Østergaard M. Can imaging be used for inflammatory arthritis screening? Semin Musculoskelet Radiol. 2012;16:401-9.

34. Epis O, Paoletti F, d'Errico T, et al. Ultrasonography in the diagnosis and management of patients with inflammatory arthritides. Eur J Intern Med. 2014;25:103-11.

35. Wakefield RJ, Balint PV, Szkudlarek M, et al. Musculoskeletal ultrasound including definitions for ultrasonographic pathology. J Rheumatol. 2005;32:2485-7.

36. Poggenborg RP, Terslev L, Pedersen SJ, Østergaard M. Recent advances in imaging in psoriatic arthritis. Ther Adv Musculoskelet Dis. 2011;3:43-53.

37. Olivieri I, Padula A, Scarano E, Scarpa R. Dactylitis or "sausage-shaped" digit. J Rheumatol. 2007;34:1217-22.

38. Weber U, Lambert RG, Østergaard M, Hodler J, Pedersen SJ, Maksymowych WP. The diagnostic utility of magnetic resonance imaging in spondylarthritis: an international multicenter evaluation of one hundred eighty-seven subjects. Arthritis Rheum. 2010;62:3048-58.

39. Marinoni B, Ceribelli A, Massarotti MS, Selmi C. The Th17 axis in psoriatic disease: pathogenetic and therapeutic implications. Auto Immun Highlights. 2014;5:9-19.

40. Li J, Liu L, Rui W, et al. New interleukins in psoriasis and psoriatic arthritis patients: the possible roles of interleukin-33 to interleukin-38 in disease activities and bone erosions. Dermatology. 2017;233:37-46.
41. Przepiera-Będzak H, Fischer K, Brzosko M. Serum interleukin-18, fetuin-A, soluble intercellular adhesion molecule-1, and endothelin-1 in ankylosing spondylitis, psoriatic arthritis, and SAPHO syndrome. Int J Mol Sci. 2016;17:1255. https://doi.org/ 10.3390/ijms17081255.

42. Rooney T, Murphy E, Benito M, et al. Synovial tissue interleukin-18 expression and the response to treatment in patients with inflammatory arthritis. Ann Rheum Dis. 2004;63:1393-8.

43. Jacques P, Lambrecht S, Verheugen E, et al. Proof of concept: enthesitis and new bone formation in spondyloarthritis are driven by mechanical strain and stromal cells. Ann Rheum Dis. 2014;73:437-45.

44. Sherlock JP, Joyce-Shaikh B, Turner SP, et al. IL-23 induces spondyloarthropathy by acting on ROR- $\gamma \mathrm{t}^{+}$ $\mathrm{CD}^{+} \mathrm{CD}^{-} \mathrm{CD}^{-}$entheseal resident $\mathrm{T}$ cells. Nat Med. 2012;18:1069-76.

45. Reinhardt A, Yevsa T, Worbs T, et al. Interleukin-23dependent $\gamma / \delta \mathrm{T}$ cells produce interleukin-17 and accumulate in the enthesis, aortic valve, and ciliary body in mice. Arthritis Rheumatol. 2016;68:2476-86.

46. Costa L, Caso F, Cantarini L, Del Puente A, Scarpa R, Atteno M. Efficacy of tocilizumab in a patient with refractory psoriatic arthritis. Clin Rheumatol. 2014;33:1355-7.

47. Hughes M, Chinoy H. Successful use of tocilizumab in a patient with psoriatic arthritis. Rheumatology (Oxford). 2013;52:1728-9.

48. Ogata A, Umegaki N, Katayama I, Kumanogoh A, Tanaka T. Psoriatic arthritis in two patients with an inadequate response to treatment with tocilizumab. Jt Bone Spine. 2012;79:85-7.

49. Raychaudhuri SP, Raychaudhuri SK. Mechanistic rationales for targeting interleukin-17A in spondyloarthritis. Arthritis Res Ther. 2017;19:51.

50. Menon B, Gullick NJ, Walter GJ, et al. Interleukin$17+\mathrm{CD} 8+\mathrm{T}$ cells are enriched in the joints of patients with psoriatic arthritis and correlate with disease activity and joint damage progression. Arthritis Rheumatol. 2014;66:1272-81.

51. Cretu D, Prassas I, Saraon P, et al. Identification of psoriatic arthritis mediators in synovial fluid by quantitative mass spectrometry. Clin Proteomics. 2014;11:27.

52. Cantini F, Niccoli L, Nannini C, Kaloudi O, Bertoni $\mathrm{M}$, Cassarà E. Psoriatic arthritis: a systematic review. Int J Rheum Dis. 2010;13:300-17.

53. Mease P. TNF $\alpha$ therapy in psoriatic arthritis and psoriasis. Ann Rheum Dis. 2004;63:755-8. 
54. Generali E, Scirè CA, Favalli EG, Selmi C. Biomarkers in psoriatic arthritis: a systematic literature review. Expert Rev Clin Immunol. 2016;12:651-60.

55. Chiu YG, Ritchlin CT. Characterization of DCSTAMP+ cells in human bone marrow. J Bone Marrow Res. 2013;1. https://doi.org/10.4172/23298820.1000127.

56. Grcevic D, Jajic Z, Kovacic N, et al. Peripheral blood expression profiles of bone morphogenetic proteins, tumor necrosis factor-superfamily molecules, and transcription factor Runx 2 could be used as markers of the form of arthritis, disease activity, and therapeutic responsiveness. J Rheumatol. 2010;37:246-56.

57. Jadon DR, Nightingale AL, McHugh NJ, Lindsay MA, Korendowych E, Sengupta R. Serum soluble bone turnover biomarkers in psoriatic arthritis and psoriatic spondyloarthropathy. J Rheumatol. 2015;42:21-30.

58. Dalbeth N, Pool B, Smith T, et al. Circulating mediators of bone remodeling in psoriatic arthritis: implications for disordered osteoclastogenesis and bone erosion. Arthritis Res Ther. 2010;12:R164.

59. Riente L, Carli L, Delle Sedie A. Ultrasound imaging in psoriatic arthritis and ankylosing spondylitis. Clin Exp Rheumatol. 2014;32:S26-33.

60. Forney MC, Winalski CS, Schils JP. Magnetic resonance imaging of inflammatory arthropathies of peripheral joints. Top Magn Reson Imaging. 2011;22:45-59.

61. Perrotta FM, Astorri D, Zappia M, Reginelli A, Brunese L, Lubrano E. An ultrasonographic study of enthesis in early psoriatic arthritis patients naive to traditional and biologic DMARDs treatment. Rheumatol Int. 2016;36:1579-83.

62. Wittkowski KM, Leonardi C, Gottlieb A, et al. Clinical symptoms of skin, nails, and joints manifest independently in patients with concomitant psoriasis and psoriatic arthritis. PLoS One. 2011;6:e20279.

63. de Vlam K, Gottlieb AB, Mease PJ. Current concepts in psoriatic arthritis: pathogenesis and management. Acta Derm Venereol. 2014;94:627-34.

64. Simon D, Faustini F, Kleyer A, et al. Analysis of periarticular bone changes in patients with cutaneous psoriasis without associated psoriatic arthritis. Ann Rheum Dis. 2016;75:660-6.

65. Takata T, Takahashi A, Taniguchi Y, Terada Y, Sano S. Detection of asymptomatic enthesitis in psoriasis patients: an onset of psoriatic arthritis? J Dermatol. 2016;43:650-4.
66. Salvarani C, Cantini F, Olivieri I, et al. Isolated peripheral enthesitis and/or dactylitis: a subset of psoriatic arthritis. J Rheumatol. 1997;24:1106-10.

67. Garrido-Cumbrera M, Hillmann O, Mahapatra R, et al. Improving the management of psoriatic arthritis and axial spondyloarthritis: roundtable discussions with healthcare professionals and patients. Rheumatol Ther. 2017;4:219-31.

68. Tillett W, Jadon D, Shaddick G, et al. Smoking and delay to diagnosis are associated with poorer functional outcome in psoriatic arthritis. Ann Rheum Dis. 2013;72:1358-61.

69. Gladman DD, Thavaneswaran A, Chandran V, Cook RJ. Do patients with psoriatic arthritis who present early fare better than those presenting later in the disease? Ann Rheum Dis. 2011;70:2152-4.

70. Gossec L, Smolen JS, Ramiro S, et al. European League Against Rheumatism (EULAR) recommendations for the management of psoriatic arthritis with pharmacological therapies: 2015 update. Ann Rheum Dis. 2016;75:499-510.

71. Coates LC, Moverley AR, McParland L, et al. Effect of tight control of inflammation in early psoriatic arthritis (TICOPA): a UK multicentre, open-label, randomised controlled trial. Lancet. 2015;386:2489-98.

72. Kirkham B, de Vlam K, Li W, et al. Early treatment of psoriatic arthritis is associated with improved patient-reported outcomes: findings from the etanercept PRESTA trial. Clin Exp Rheumatol. 2015;33:11-9.

73. Tan WS, Kelly S, Pitzalis C. Targeted therapies: what they teach us about the pathogenesis of psoriasis and psoriatic arthritis. Expert Rev Clin Immunol. 2017;13:207-22.

74. Eyre S, Orozco G, Worthington J. The genetics revolution in rheumatology: large scale genomic arrays and genetic mapping. Nat Rev Rheumatol. 2017;13:421-32.

75. Addimanda O, Possemato N, Caruso A, Pipitone N, Salvarani C. The role of tumor necrosis factor- $\alpha$ blockers in psoriatic disease. Therapeutic options in psoriatic arthritis. J Rheumatol Suppl. 2015;93:73-8.

76. Cantini F, Niccoli L, Nannini C, et al. Frequency and duration of clinical remission in patients with peripheral psoriatic arthritis requiring second-line drugs. Rheumatology (Oxford). 2008;47:872-6.

77. McInnes IB, Mease PJ, Kirkham B, et al. Secukinumab, a human anti-interleukin-17A monoclonal antibody, in patients with psoriatic arthritis 
(FUTURE 2): a randomised, double-blind, placebocontrolled, phase 3 trial. Lancet. 2015;386:1137-46.

78. Ritchlin C, Rahman P, Kavanaugh A, et al. Efficacy and safety of the anti-IL-12/23 p40 monoclonal antibody, ustekinumab, in patients with active psoriatic arthritis despite conventional non-biological and biological anti-tumour necrosis factor therapy: 6-month and 1-year results of the phase 3, multicentre, double-blind, placebo-controlled, randomised PSUMMIT 2 trial. Ann Rheum Dis. 2014;73:990-9.

79. Nash P, Kirkham B, Okada M, et al. Ixekizumab for the treatment of patients with active psoriatic arthritis and an inadequate response to tumour necrosis factor inhibitors: results from the 24-week randomised, double-blind, placebo-controlled period of the SPIRIT-P2 phase 3 trial. Lancet. 2017;389:2317-27.

80. van Baarsen LG, Lebre MC, van der Coelen D, et al. Heterogeneous expression pattern of interleukin 17A (IL-17A), IL-17F and their receptors in synovium of rheumatoid arthritis, psoriatic arthritis and osteoarthritis: possible explanation for nonresponse to anti-IL-17 therapy? Arthritis Res Ther. 2014;16:426.

81. Mease PJ. Measures of psoriatic arthritis: Tender and Swollen Joint Assessment, Psoriasis Area and Severity Index (PASI), Nail Psoriasis Severity Index (NAPSI), Modified Nail Psoriasis Severity Index (mNAPSI), Mander/Newcastle Enthesitis Index (MEI), Leeds Enthesitis Index (LEI), Spondyloarthritis Research Consortium of Canada (SPARCC), Maastricht Ankylosing Spondylitis Enthesis Score (MASES), Leeds Dactylitis Index (LDI), Patient Global for Psoriatic Arthritis, Dermatology Life Quality Index (DLQI), Psoriatic Arthritis Quality of Life (PsAQOL), Functional Assessment of Chronic Illness Therapy-Fatigue (FACIT-F), Psoriatic Arthritis Response Criteria (PsARC), Psoriatic Arthritis Joint Activity Index
(PsAJAI), Disease Activity in Psoriatic Arthritis (DAPSA), and Composite Psoriatic Disease Activity Index (CPDAI). Arthritis Care Res (Hoboken). 2011;63(Suppl 11):S64-85.

82. Mease PJ, Kavanaugh A, Coates LC, et al. Prediction and benefits of minimal disease activity in patients with psoriatic arthritis and active skin disease in the ADEPT trial. RMD Open. 2017;3:e000415.

83. Helliwell PS, FitzGerald O, Fransen J, et al. The development of candidate composite disease activity and responder indices for psoriatic arthritis (GRACE project). Ann Rheum Dis. 2013;72:986-91.

84. Mease PJ, Coates LC. Considerations for the definition of remission criteria in psoriatic arthritis. Semin Arthritis Rheum. 2018;47:786-96.

85. Haddad A, Thavaneswaran A, Ruiz-Arruza I, et al. Minimal disease activity and anti-tumor necrosis factor therapy in psoriatic arthritis. Arthritis Care Res (Hoboken). 2015;67:842-7.

86. Mies Richie A, Francis ML. Diagnostic approach to polyarticular joint pain. Am Fam Physician. 2003;68:1151-60.

87. Maman E, Masson-Behar V, Coustet B, Palazzo E, Dieude $\mathrm{P}$, Ottaviani S. Enthesitis in rheumatoid arthritis and spondyloarthritis: an ultrasound study. Ann Rheum Dis. 2016;75:1226.

88. Wenker K, Quint JM. Ankylosing spondylitis. Treasure Island: StatPearls; 2018.

89. Queiro-Silva R, Torre-Alonso JC, Tinturé-Eguren T, López-Lagunas I. A polyarticular onset predicts erosive and deforming disease in psoriatic arthritis. Ann Rheum Dis. 2003;62:68-70.

90. Raddatz DA, Mahowald ML, Bilka PJ. Acute polyarticular gout. Ann Rheum Dis. 1983;42:117-22. 